\title{
Esophagogastric Junction Outflow Obstruction Transformed to Type II Achalasia
}

\author{
In Seub Shin, Yang Won Min, and Poong-Lyul Rhee* \\ Department of Medicine, Samsung Medical Center, Sungkyunkwan University School of Medicine, Seoul, Korea
}

A 53-year-old woman presented with dysphagia for 2 months. She denied any acid regurgitation or heartburn symptoms. Esophagogastroduodenoscopy revealed no abnormal findings. However, bird-beak appearance of the distal esophagus was noticed on the esophagography. For evaluation of esophageal motility disorders, she underwent esophageal high resolution manometry (HRM). On the HRM, the integrated relaxation pressure was elevated and accompanied by compartmentalized esophageal pressurization,while esophageal body peristalsis, distal contractile integral, and distal latency were normal (Figure A). According to the Chicago classification (CC), ${ }^{1}$ she was diagnosed with esophagogastric junction outflow obstruction (EGJOO). ${ }^{1}$ The patient's dysphagia was tolerable without specific treatment. However, the dysphagia became aggravated 1 year later. She underwent esophagography and HRM again. On the HRM, panesophageal pressurization with failed lower esophageal sphincter relaxation was noticed (Figure B).
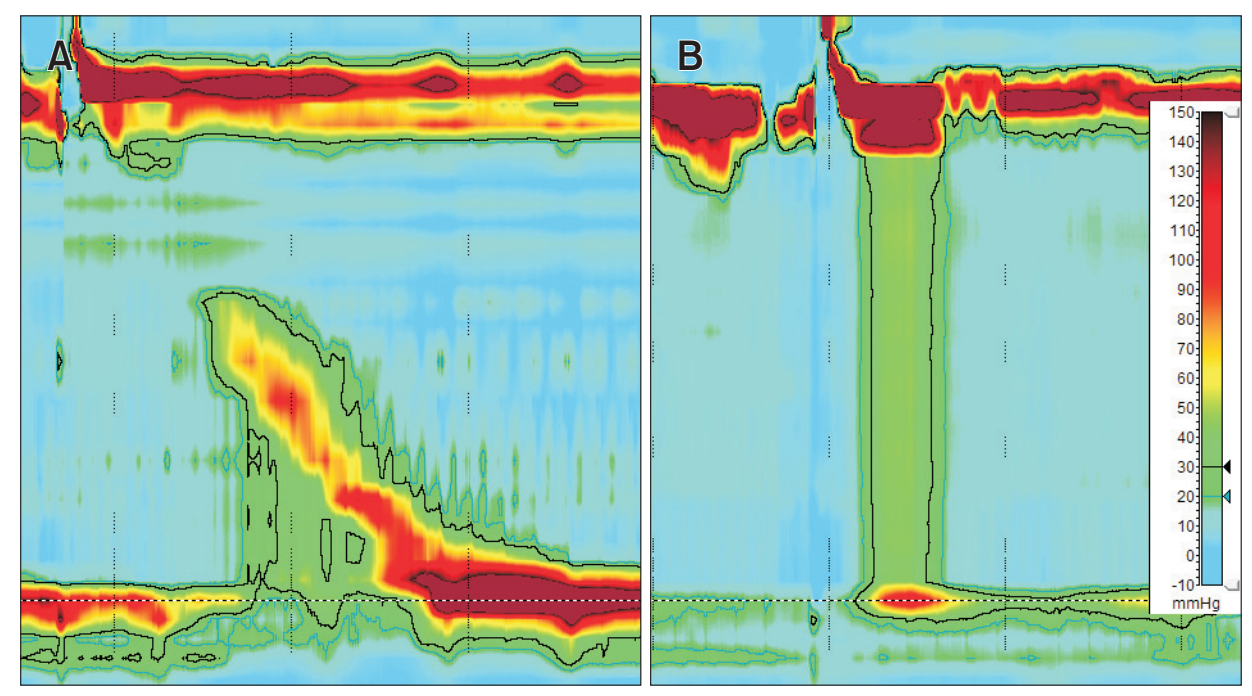

Figure. Esophageal high-resolution manometry (HRM) findings of a patient present with dysphagia intially and 1 year later. (A) Esophagogastric junction outflow obstruction. HRM shows preserved esophageal body peristalsis but elevated integrated relaxation pressure (IRP, median $23.8 \mathrm{mmHg}$ ). (B) Type II achalasia. Follow-up HRM 1 year later shows panesophageal pressurization with elevated IRP (median $24.55 \mathrm{mmHg}$ ).

Received: March 8, 2016 Revised: None Accepted: March 12, 2016

() This is an Open Access article distributed under the terms of the Creative Commons Attribution Non-Commercial License (http://creativecommons. org/licenses/by-nc/4.0) which permits unrestricted non-commercial use, distribution, and reproduction in any medium, provided the original work is properly cited.

*Correspondence: Poong-Lyul Rhee, MD, PhD

Department of Medicine, Samsung Medical Center, Sungkyunkwan University School of Medicine, 81 Irwon-ro, Gangnam-gu, Seoul 06351, Korea

Tel: +82-2-3410-3409, Fax: +82-2-3410-6983, E-mail: plrhee@skku.edu 
According to the $\mathrm{CC}$ she was diagnosed as type 2 achalasia. After pneumatic balloon dilatation, her symptoms improved (Eckardt score, 1$)$.

The CC defines EGJOO as the presence of some instances of intact or weak peristalsis, elevated median integrated relaxation pressure above $15 \mathrm{mmHg}$, and discrepancy to the criteria of achalasia. ${ }^{1}$ The revised $\mathrm{CC}$ addresses the potential etiology of EGJOO including early form of achalasia, mechanical obstruction, esophageal wall stiffness, or manifestation of hiatal hernia. ${ }^{2}$ Due to the loose current definition of EGJOO, heterogeneous groups are included in this category. Indeed, EGJOO is presented with various symptoms. In recent studies, patients with EGJOO presented with dysphagia in $36 \%$, heartburn/regurgitation in $25 \%$, atypical symptoms of gastroesophageal reflux disease in $21 \%$, and chest pain in $11 \%{ }^{2,3}$ In addition, various clinical courses of EGJOO ranging from spontaneous symptom resolution to requirement of myotomy were observed. $^{2-4}$ EGJOO is just a manometric diagnosis. Thus, we need to investigate the underlying etiology further to manage the patients with EGJOO appropriately. Herein we present a EGJOO patient who transformed to a type II achalasia with time, which may be the most important etiology within the EGJOO category. Although the significance remains unclear, compartmentalized esophageal pressurization was observed in this case. In the future, it would be interesting to evaluate the role of compartmentalized esophageal pressurization in patients with EGJOO.

\section{Financial support: None}

\section{Conflicts of interest: None}

Author contributions: In Seup Shin contributed to data analysis and drafted the manuscript; Yang Won Min contributed to data interpretation and edited the manuscript; and Poong-Lyul Rhee designed and coordinated the study and performed critical revision of the manuscript.

\section{References}

1. Kahrilas PJ, Bredenoord AJ, Fox M, et al. The Chicago Classification of esophageal motility disorders, v3.0. Neurogastroenterol Motil 2015;27:160-174.

2. Pérez-Fernández MT, Santander C, Marinero A, Burgos-Santamaria D, Chavarria-Herbozo C. Characterization and follow-up of esophagogastric junction outflow obstruction detected by high resolution manometry. Neurogastroenterol Motil 2016;28:116-126.

3. Sodikoff JB, Lo AA, Shetuni BB, Kahrilas PJ, Yang GY, Pandolfino JE. Histopathologic patterns among achalasia subtypes. Neurogastroenterol Motil 2016;28:139-145.

4. Zerbib F, Roman S. Current Therapeutic Options for Esophageal Motor Disorders as Defined by the Chicago Classification. J Clin Gastroenterol $2015 ; 49: 451-460$ 